\title{
LA PRODUCCIÓN ESPECIALIZADA DE LA CERÁMICA DOMÉSTICA Y RITUAL MOCHICA
}

\author{
Hélène Bernier ${ }^{1}$
}

\section{* Introducción}

Resumen

A partir del siglo III DC la sociedad mochica estableció en la costa norte de Perú el primer Estado expansionista del área andina. En su capital urbana Huacas de Moche, talleres de producción artesanal han sido recién descubiertos, mientras que miles de objetos producidos por artesanos especializados se han hallado en contextos de consumo, tanto domésticos como funerarios. Este artículo trata sobre la producción de cerámica utilitaria y ritual mochica, y su organización en el sitio Huacas de Moche. Los diversos talleres serán descritos junto con varios contextos culturales de producción especializada de cerámica. Asimismo, se discutirá la distribución y el consumo de vasijas y objetos fabricados por ceramistas especializados y, a través del análisis de los patrones de consumo, intentaremos comprender los roles sociales de estos especialistas en los ámbitos económicos, políticos y rituales de la sociedad mochica.

Palabras claves: mochica - Perú - cerámica artesanos especializados.

\begin{abstract}
From the third Century AD, the Mochica society became the first expansionist State to develop on the Peruvian north coast. In the urban capital of Huacas de Moche, recent excavations revealed the existence of workshops dedicated to craft production. Thousands of objects produced by craft specialists were also found in various domestic and funerary contexts. This article examines the organization of specialized production of domestic and ritual ceramic objects at Huacas de Moche. Workshops will be described

and the contexts of ceramic production will be discussed. The

distribution and consumption of vessels and objects made by specialized ceramists will be examined as well. Through the analysis of consumption patterns, we will discuss the social roles played by ceramists in the economic, political, and ritual spheres of the Mochica society.
\end{abstract}

Key words: mochica - Peru - ceramics - craft specialists.

Recibido: marzo 2007. Aceptado: enero 2009.
La presencia de artesanos especializados ha constituido un criterio importante en la definición de los Estados prehistóricos (Childe 1950; Service 1962). Durante las últimas décadas, la producción artesanal especializada ha llamado particularmente la atención de varios investigadores que estudian el desarrollo de las sociedades complejas (Evans 1978; Tosi 1984; Brumfiel y Earle 1987; Clark y Parry 1990; Costin 1991; Helms 1993; Clark 1995; Costin y Wright 1998). El fenómeno de la especialización hace referencia a situaciones dentro de las cuales un artesano está alejado completamente o en parte de la producción alimenticia, debiendo en consecuencia asegurar toda o una parte de su subsistencia con el intercambio de los bienes materiales que produce (Costin 1991; Evans 1978; Muller 1984). Existe entonces una relación de interdependencia entre los artesanos especializados y los consumidores de sus bienes.

Este artículo trata sobre la producción especializada de cerámica doméstica y ritual mochica en el sitio Huacas de Moche, ubicado en la costa norte de Perú. En primer lugar, expondremos algunos aspectos teóricos esenciales dentro del análisis de la especialización del trabajo y, segundo, describiremos los talleres de cerámica del sitio Huacas de Moche, así como la distribución y el consumo de vasijas realizadas por ceramistas especializados. Finalmente, se discutirán los contextos sociales en los cuales trabajaron los ceramistas y las necesidades económicas, políticas

\footnotetext{
${ }^{1}$ Department of Art History and Archaeology, University of Maryland, College Park, MD 20742, ESTADOS UNIDOS. Email: helenebernier13@ yahoo.ar
} 
y rituales ligadas a la producción de cerámica en la sociedad mochica.

\section{LOS MOCHICAS}

La sociedad mochica se desarrolló en el desierto de la costa norte peruana entre los siglos I y VIII DC, estableciendo pueblos y centros urbanos en los valles fértiles formados por los ríos que descienden desde los Andes hasta el Océano Pacífico. Los arqueólogos ahora reconocen la división del territorio mochica en dos regiones culturales distintas: los mochicas del norte y los del sur. Aunque los pobladores de ambas regiones presentaban muchas características comunes en su religión, rituales e iconografía, también presentaban marcadas diferencias en cuanto a sus tradiciones cerámicas y organizaciones políticas respectivas (Castillo y Donnan 1994; Shimada 1994a; Castillo y Uceda 2008). Los mochicas del sur formaron el primer Estado prehispánico expansionista y centralizado en América del Sur a partir del cuarto siglo de nuestra era, correspondiente a la fase Moche IV (Hastings y Moseley 1975; Donnan y Mackey 1978; Topic 1982; Wilson 1988; Moseley 1992; Bawden 1996; Chapdelaine 2001, 2002, 2003; Billman 2002). En contraste, el territorio mochica norte parece haber estado fragmentado en tres sistemas políticos independientes localizados en los valles de Piura, Lambayeque y Jequetepeque (Figura 1).

El sitio Huacas de Moche es considerado como la capital urbana o como un centro de primera importancia en el Estado mochica sur. Está caracterizado por una planicie de 60 ha bordeada por el cerro Blanco al este, el río Moche al norte y por dos plataformas monumentales de adobes denominadas Huaca del Sol y Huaca de la Luna (Figura 2). Varios metros por debajo la superficie arenosa de la planicie se encuentra un extenso sector urbano compuesto de conjuntos residenciales, calles y plazas públicas (Figura 3). Las excavaciones en los sectores monumentales y residenciales sugieren que el sitio Huacas de Moche fue un centro neurálgico de actividades administrativas, políticas, ceremoniales y de producción artesanal (Chapdelaine 2003; Bernier
2005). En el sitio vivían miembros de la élite dirigente que mantenían la autoridad y la continuidad de las actividades rituales y de las instituciones estatales. También vivía una numerosa población urbana compuesta por linajes y grupos corporativos cuyos miembros, caracterizados por estatus socioeconómicos desiguales y por roles sociales diversificados, estaban íntimamente relacionados con las funciones religiosas, económicas y políticas de la ciudad e integrados a la estructura social mochica (Chapdelaine 2001, 2002, 2003).

Los datos arqueológicos de esta investigación provienen del sector urbano del sitio Huacas de Moche, de niveles estratigráficos correspondientes a la fase de apogeo Moche IV. Los datos fueron recolectados desde 1994 en el marco de dos proyectos de investigación: El proyecto Zona Urbana Moche, dirigido por C. Chapdelaine de la Universidad de Montreal (Chapdelaine 1997, 2000, 2001, 2002, 2003), tenía como objetivo el estudio del urbanismo y de la arquitectura doméstica mochica. Estaba integrado al programa de gran envergadura Proyecto Arqueológico Huaca de la Luna dirigido por S. Uceda y R. Morales de la Universidad Nacional de Trujillo (Uceda et al. 1997, 1998, 2000, 2003, 2006; Uceda 2001; Uceda y Tufinio 2003).

\section{• Aspectos teóricos}

La organización de la producción artesanal es muy diversa y se puede analizar considerando varios factores interrelacionados, así como la intensidad (producción a tiempo completo o parcial), el grado (producción a pequeña o gran escala), el contexto (producción afiliada o independiente) y las categorías de bienes producidos. Estos dos últimos factores son los que importan en este estudio.

El contexto de la producción artesanal hace referencia al grado de filiación entre los artesanos y la élite dirigente, como también a la categoría de consumidores para quienes son destinados los bienes producidos. Dentro del contexto de filiación, los artesanos especializados producen para un grupo de consumidores seleccionados y restringidos, bajo el control de jefes 


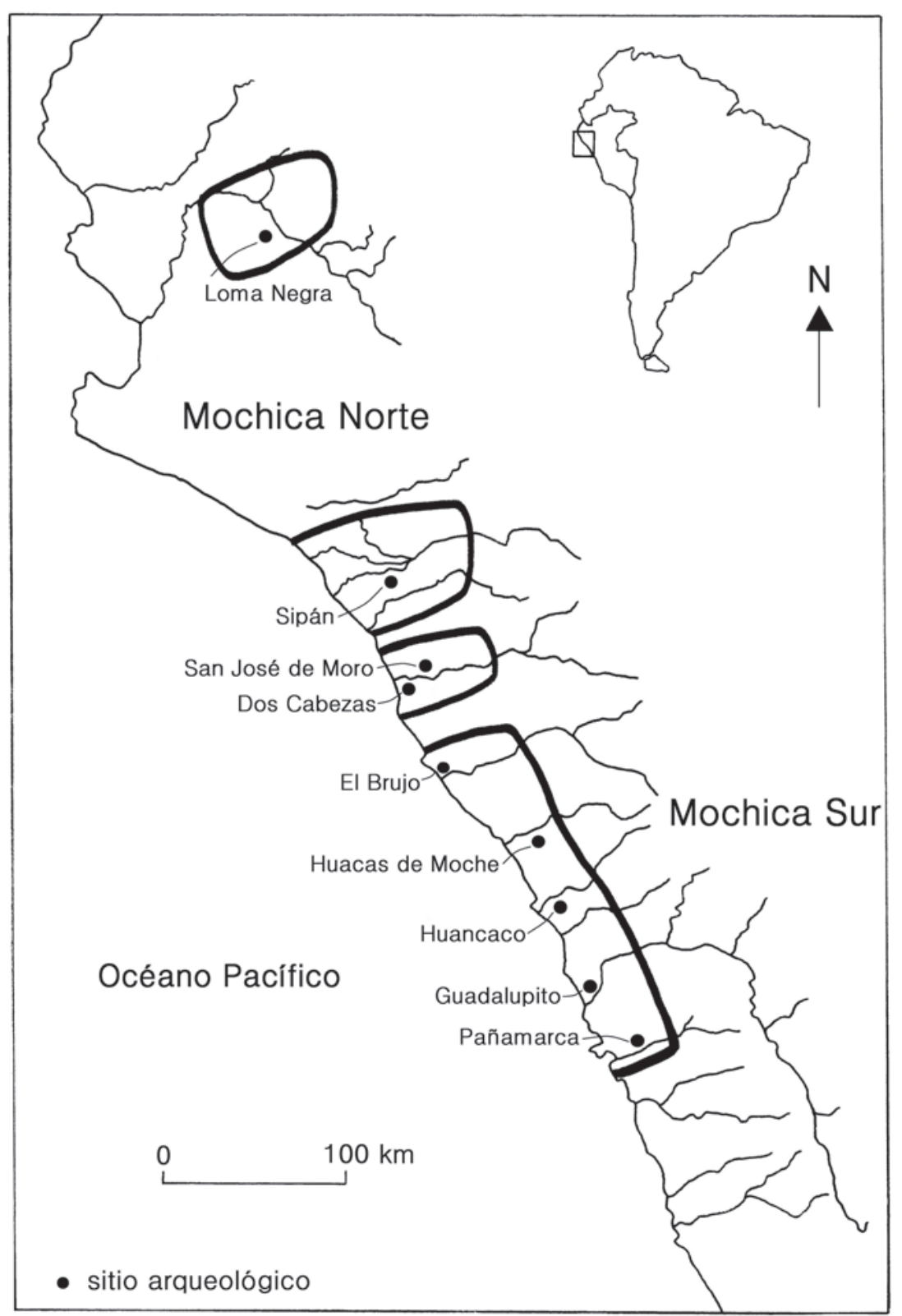

Figura 1. Territorio del Estado mochica durante la fase Moche IV. Dibujo de la autora.

pertenecientes a la élite. En el contexto independiente, los artesanos pueden servir a la población en general y poseen los derechos sobre los bienes que producen (Gero 1983; Brumfiel y Earle 1987; Clark y Parry 1990; Costin 1991; Costin y Hagstrum 1995).

La producción de bienes utilitarios responde a necesidades esenciales de la vida cotidiana. Estos bienes son distintos de los objetos de prestigio, que transmiten un mensaje simbólico (Peebles y Kus 1977; Clark 1986; Brumfiel y Earle 1987; Costin 1991; Yerkes 1991; Hayden 1998). Además de poseer una naturaleza y una función distintas, las dos categorías de bienes responden a dinámicas de producción diferentes. En el caso de la producción de bienes utilitarios, el especialista administra su propia economía y su eficiencia, ahorrando 


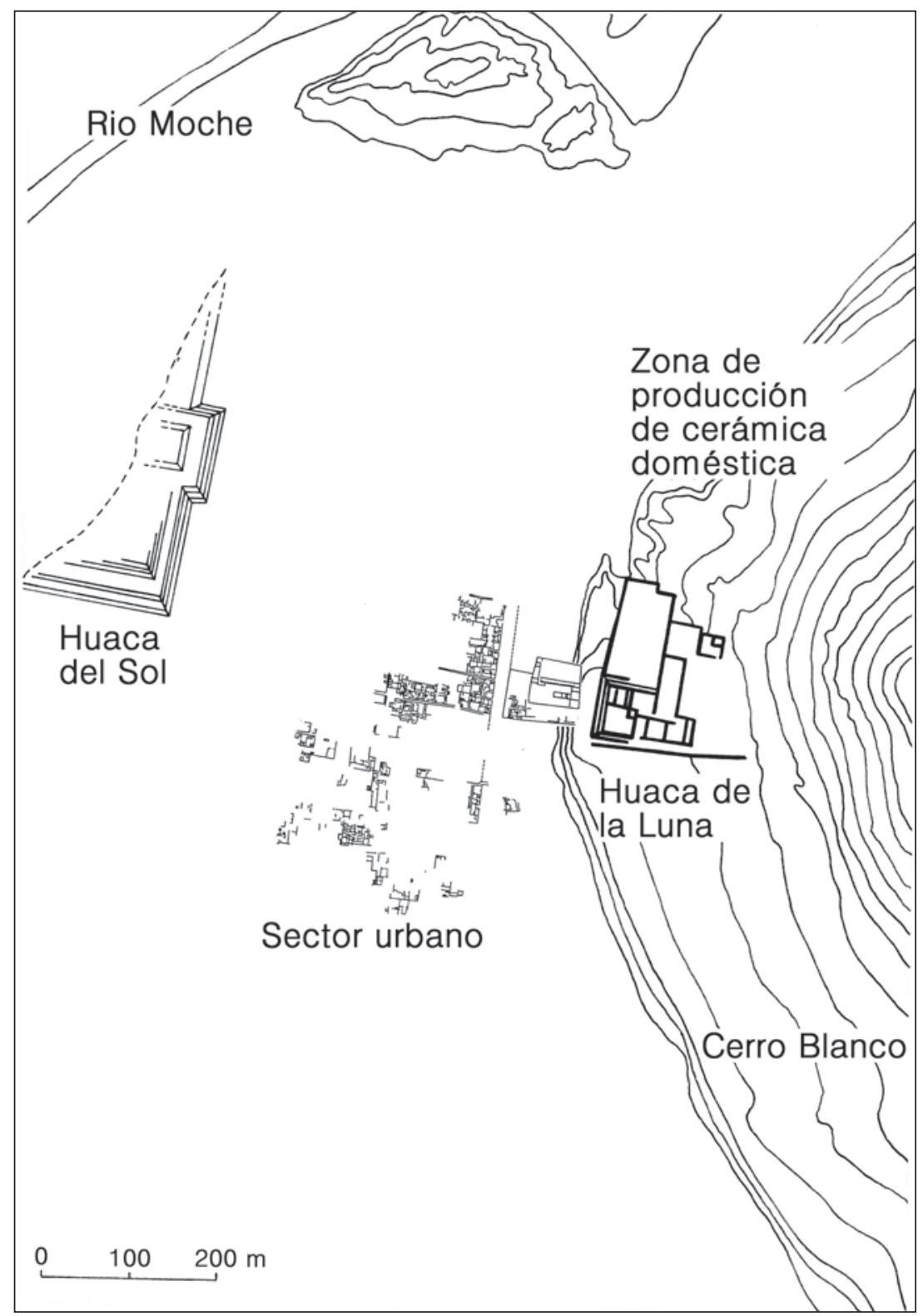

Figura 2. Plano general del sitio Huacas de Moche. Dibujo de la autora.

tiempo, energía y materia prima. La producción de bienes de prestigio, que sirven para resolver diferentes problemas sociales, responde a la lógica contraria. El especialista puede invertir una suma importante de tiempo y de trabajo, aumentando también el valor material y simbólico de los objetos.

De una sociedad a la otra, la producción especializada responde a necesidades económicas, ecológicas, sociales y políticas, relacionadas con los diferentes estratos sociales de la población. Los fundamentos económicos de la especialización artesanal están ligados a conceptos de eficacia, de intensidad y de productividad. También en las sociedades no industriales, la situación es mucho más económica en términos de energía invertida y de tiempo dedicado a la producción cuando una clase de objetos es fabricada de forma intensiva por un pequeño número de individuos especializados, que cuando son fabricados de manera ocasional por un solo individuo (Evans 1978; Hagstrum 1985). Además, el desarrollo 


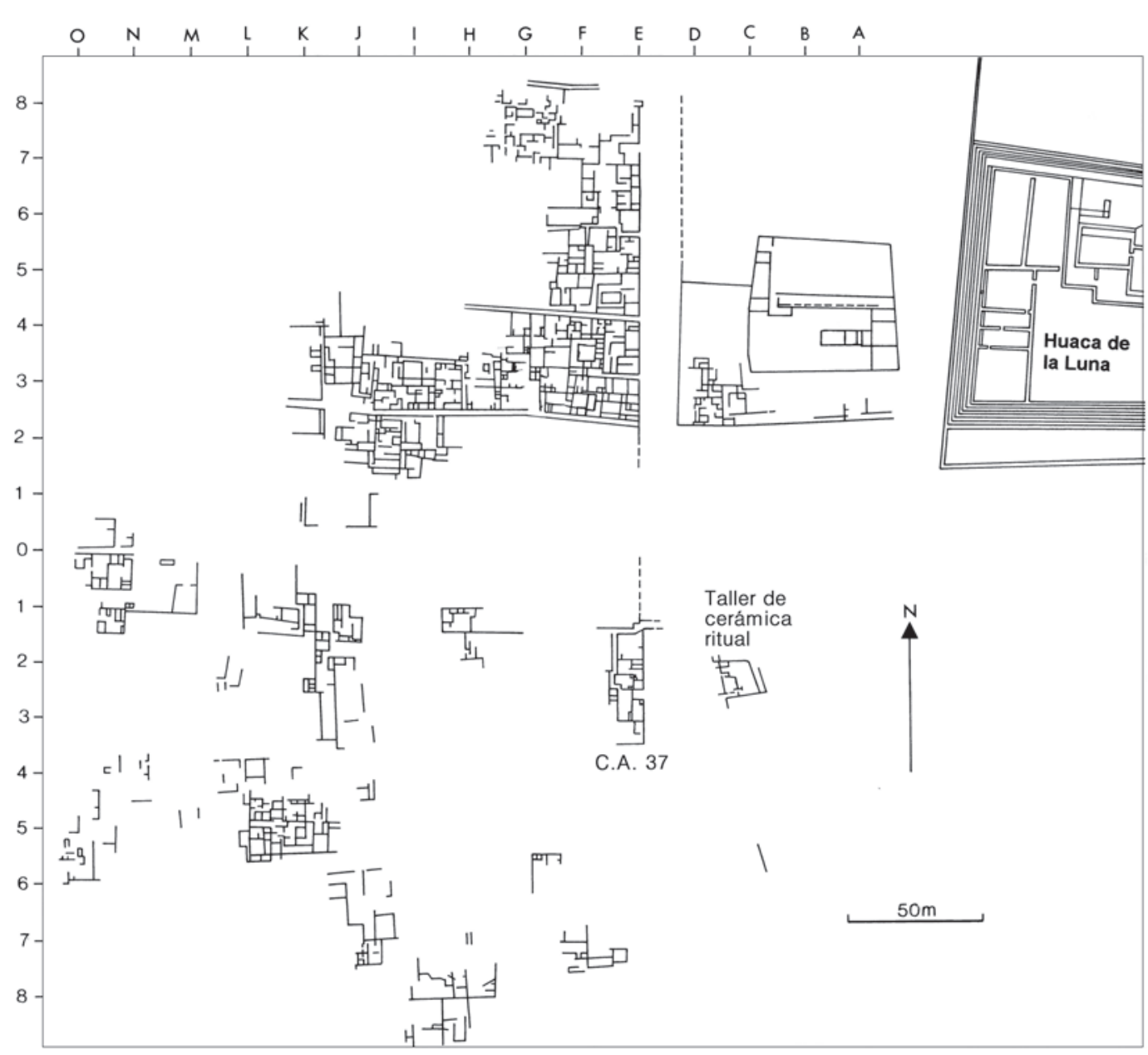

Figura 3. Plano del sector urbano de Huacas de Moche. Dibujo de la autora.

del trabajo especializado ocasiona una mejoría de la tecnología de los bienes producidos, ya que el artesano llega a conocer bien su materia con la concentración del trabajo (Service 1962). La eficacia superior de los especialistas en la producción de alimentos o de bienes materiales concede una ventaja económica a las sociedades jerarquizadas en las cuales el trabajo es especializado (Evans 1978).

Los fundamentos adaptativos de la especialización artesanal se refieren mayormente a los bienes utilitarios. En este sentido, la especialización artesanal asociada al intercambio entre regiones de bienes materiales esenciales permite una mejor adaptación a la repartición desigual de los recursos naturales en el territorio. También permite la explotación ventajosa de las diferencias tecnológicas de un grupo y otro (Brumfiel y Earle 1987).

Finalmente, el control del trabajo de los artesanos especializados es una oportunidad política que la élite aprovecha con el objetivo de consolidar su poder. Cuando las motivaciones políticas tienen prelación sobre la voluntad de eficacia económica o adaptativa, la élite se vuelve la primera beneficiaria de la especialización artesanal. Los grupos dirigentes emplean la producción artesanal de manera estratégica para crear y mantener la desigualdad social, aumentando y legitimando su poder, reforzando las coaliciones políticas y las instituciones de control (Brumfiel y Earle 1987; Junker 1999). 


\section{- Datos arqueológicos en Huacas de Moche: TAlleres de PRODUCCiÓN}

Varios talleres especializados en el trabajo de cerámica, metales, piedra y posiblemente textiles han sido descubiertos en el sitio Huacas de Moche (Uceda y Armas 1997, 1998; Chapdelaine 1998; Jara 2000; Chapdelaine et al. 2001, 2003; Chiguala et al. 2004; Bernier 2005, 2008; Rengifo y Rojas 2008). Estos talleres nos informan sobre varios aspectos de la organización de la producción artesanal. Se definen por indicios directos y tangibles como hornos, así como concentraciones de materias primas, herramientas, residuos de fabricación, objetos no terminados y objetos rotos o fallados (Evans 1978; Tosi 1984; Costin 1991).

Dos talleres de cerámica se conocen en el sitio Huacas de Moche. El primero, ubicado en la parte este del sector urbano, estuvo destinado a la producción de objetos de cerámica fina y decorada (ver Figura 3). Los objetos producidos en mayor abundancia en este taller fueron las figurinas femeninas moldeadas y los instrumentos musicales, como silbatos, ocarinas, trompetas y sonajas. También se produjeron adornos figurativos, piruros y vasijas decoradas como botellas y cántaros. En el taller además se descubrieron vasijas decoradas con escenas pintadas e imágenes tridimensionales, entre las cuales son frecuentes las representaciones de cacería y de guerreros, las vasijas retrato y las escenas eróticas (Uceda y Armas 1998).

Todas las etapas de fabricación de los objetos señalados se ejecutaron en el mismo lugar, usándose una arcilla local (Chapdelaine et al. 1995): la preparación de desgrasantes y de pastas, la creación de matrices, la fabricación de los moldes y de los objetos, la preparación y aplicación de engobes, el secado, la cocción y el almacenamiento de los productos terminados. El conjunto de indicios de producción incluye, por ejemplo, la zona de combustión, al igual que las numerosas herramientas: más de mil moldes (Figura 4), manos y metates, discos de alfareros, alisadores, pulidores, bruñidores y tinajas para almacenar agua y arcilla (Tabla 1) (Uceda y Armas 1997, 1998; Armas 1998). La ocupación del taller alfarero se extendió verticalmente

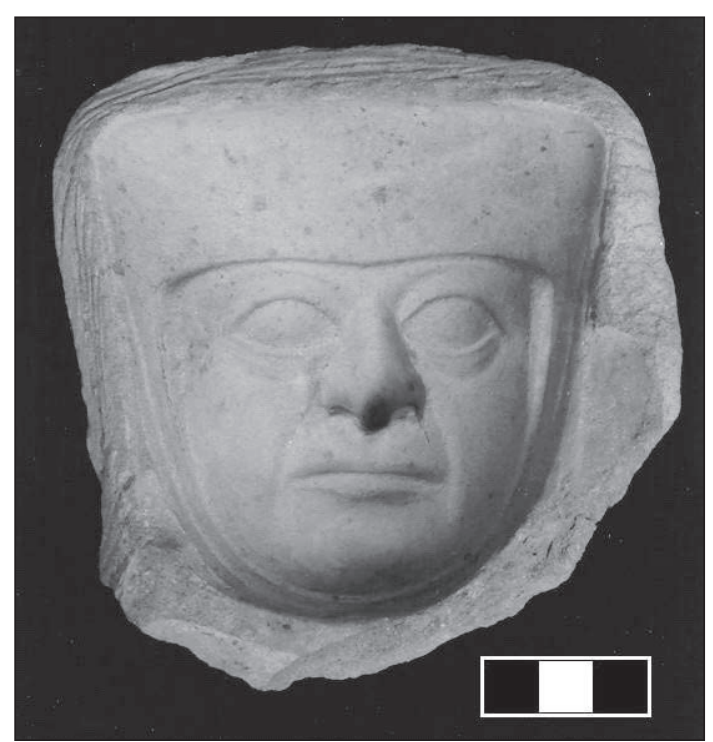

Figura 4. Molde de un "vaso retrato" mochica.

Fotografía de la autora.

sobre tres pisos pertenecientes a la fase Moche IV. El taller no fue excavado completamente en ninguna de las ocupaciones, pero sabemos que la más reciente corresponde a varios ambientes pertenecientes a uno o a varios conjuntos arquitectónicos. La superficie del taller se extiende más allá del área excavada de $300 \mathrm{~m}^{2}$ (Uceda y Armas 1997, 1998; Armas 1998).

El taller de cerámica fina del sitio Huacas de Moche no es el único conocido para el Estado mochica sur. En el valle de Chicama se documentó un segundo sitio especializado en la producción de cerámica fina. En el sitio de Cerro Mayal, ubicado a $1.5 \mathrm{~km}$ del centro ceremonial de Mocollope, un grupo de ceramistas especializados produjo vasijas decoradas, figurinas moldeadas, instrumentos musicales y ornamentos muy semejantes a los elaborados en el taller de Huacas de Moche. El centro de producción en Cerro Mayal consistía en tres zonas funcionales distintas. En la primera se trabajaba la arcilla cruda y se moldeaban y pintaban las piezas. En la zona de cocción, que incluía un fogón, se han hallado concentraciones de combustible (carbón vegetal) y de piezas descartadas o accidentalmente rotas. La última zona estaba dedicada al almacenaje en pequeñas estructuras de adobe, piedra y caña. En el taller de Cerro Mayal se hallaron grandes 


\begin{tabular}{|c|c|c|c|c|}
\hline Tipo de objeto & $\begin{array}{l}\text { Ocupación } 1 \\
\text { (más antigua) }\end{array}$ & $\begin{array}{l}\text { Ocupación } 2 \\
\text { (intermedia) }\end{array}$ & $\begin{array}{c}\text { Ocupación } 3 \\
\text { (superficicial) }\end{array}$ & Total \\
\hline Objetos sin cocción & 12 & 11 & $\mathbf{I}$ & 24 \\
\hline Matrices & 2 & 2 & - & 4 \\
\hline Figurinas & 6 & 9 & - & 15 \\
\hline Instrumentos musicales & 2 & - & 1 & 3 \\
\hline Vasijas rituales & 2 & - & - & 2 \\
\hline Moldes & 7 & 30 & 13 & 50 \\
\hline De figurinas & 2 & 7 & 9 & 18 \\
\hline De instrumentos musicales & 1 & 5 & 1 & 7 \\
\hline De vasijas rituales & 4 & 10 & 2 & 16 \\
\hline De pendientes & - & 8 & 1 & 9 \\
\hline Objetos terminados & 40 & 116 & 19 & 175 \\
\hline Figurinas & 29 & 49 & 14 & 92 \\
\hline Instrumentos musicales & 5 & 35 & 2 & 42 \\
\hline Vasijas rituales & 1 & 7 & 1 & 9 \\
\hline Pendientes & 5 & 25 & 2 & 32 \\
\hline Total & 59 & 157 & 33 & 249 \\
\hline
\end{tabular}

Tabla 1. Distribución de los objetos completos de cerámica directamente asociados a cada uno de los pisos del taller de cerámica fina (según Uceda y Armas 1998). No se incluyeron los objetos encontrados en las capas entre pisos.

cantidades de moldes, piezas cerámicas no cocidas y masas de arcilla cruda; estas últimas originalmente envueltas con textiles (Russel et al. 1994, 1998; Russel y Jackson 2001).

Otras zonas de producción de cerámica ritual existían en el valle de Santa. Aunque aún no se ha descubierto ningún taller especializado asociado a estructuras arquitectónicas, altas concentraciones de moldes, partes de vasijas y otras piezas con defectos de cocción y arcilla cruda (incluyendo caolín) fueron descubiertas en los sitios GUAD-88 (Taillon-Pellerin 2004) y Hacienda San José (Chapdelaine y Pimentel $2001 \mathrm{Ms}$ ).

El segundo taller de cerámica documentado en el sitio Huacas de Moche es un lugar de producción de vasijas utilitarias, ubicado justo bajo el primer afloramiento rocoso al noroeste del Cerro Blanco (ver Figura 2). Registrado por Uhle a inicios del siglo XX (Kaulicke 1998), este taller no ha sido aún excavado. Todavía es posible observar varios vestigios arquitectónicos expuestos en la superficie, asociados a concentraciones de indicios materiales que demuestran la fabricación in situ de vasijas utilitarias. En toda la superficie de este sector se pueden observar miles de fragmentos de vasijas domésticas cocidas, fragmentos crudos o con defectos de cocción, bordes de tinajas crudas, metates, manos de moler, pulidores, discos de alfareros y concentraciones de ceniza (Figura 5; Jara 2000). La gran variabilidad formal de las vasijas fragmentadas indica que en este sector eran producidas ollas y cántaros de diversos tamaños, así como tinajas de almacenaje.

\section{- Datos arqueológicos: \\ Contextos de CONSUmo}

Las excavaciones recientes en estructuras monumentales, viviendas y contextos funerarios del sector urbano de Huacas de Moche demuestran que la vida diaria en la ciudad constantemente generaba una fuerte demanda por una gran variedad de bienes materiales, especialmente aquellos producidos por ceramistas especializados. 


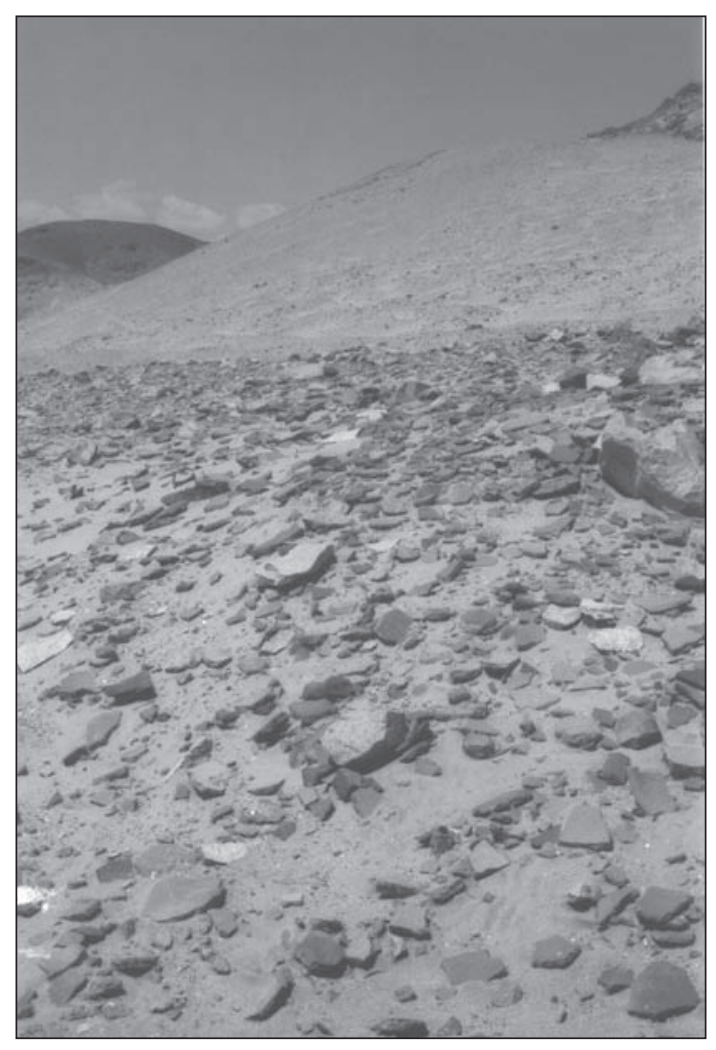

Figura 5. Vista del taller de cerámica doméstica del sitio Huacas de Moche. Fotografía de la autora.

\section{Cerámica utilitaria}

Modeladas a mano y sin embargo de formas estandardizadas, las vasijas utilitarias no decoradas fueron hechas con una pasta gruesa y tienen paredes más espesas que la cerámica ritual (Gamarra y Gayoso 2008). Según sus dimensiones y características morfológicas, las vasijas utilitarias se pueden clasificar en tres categorías generales:

1) Las ollas son vasijas de tamaño pequeño, de cuerpo esférico, gollete corto y boca ancha (Manrique y Cáceres 1989). Fáciles de mover y manipular, tienen una forma adecuada para la cocción de alimentos, con su forma abierta que favorece el acceso al contenido y su base redondeada, ligeramente aplastada, bien diseñada para conducir el calor (Henrickson y McDonald 1983; Lumbreras 1987). Las ollas del sitio Huacas de Moche están hechas con una pasta porosa (Mantha 1999); así resistían bien a los choques térmicos causados por el fuego (Figura 6).

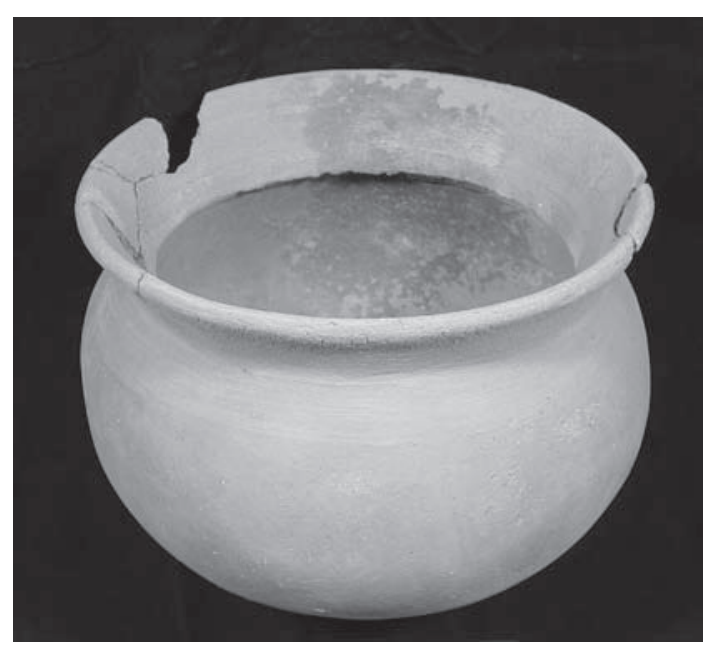

Figura 6. Olla doméstica mochica. Fotografía de Claude Chapdelaine.

2) Los cántaros son vasijas generalmente más grandes, con un gollete más alto y derecho, un cuerpo más alargado estrechándose en la base y una boca más angosta (Figura 7). Tienen paredes delgadas y son bastante ligeros en proporción a su volumen; así pueden ser movidos y manipulados con facilidad (Mantha 1999). Al igual que las ollas, sirvieron para cocer alimentos. Con su forma cerrada, eran propicios para transportar líquidos y almacenar productos fáciles de verter, tales como sal, granos o moluscos vivos conservados en agua.

3) Las tinajas son vasijas masivas de tamaño muy grande, de paredes gruesas, sin gollete, con un cuerpo ovoide y una base convexa. Las más voluminosas tienen una forma alargada con un estrechamiento ligero en el centro, donde el ceramista juntó la parte superior y la parte inferior durante su fabricación (Figura 8). Estas vasijas sirvieron para almacenar líquidos como agua o chicha (cerveza de maíz). El diámetro de su boca, generalmente de más de $30 \mathrm{~cm}$, es inferior al diámetro de su cuerpo. Su contenido está en parte protegido, pero permanece todavía accesible para introducir una escudilla. De peso considerable, las tinajas grandes se movían con dificultad y se encuentran generalmente en contextos primarios, alineadas a lo largo de muros de viviendas. Otras tinajas, no tan masivas y de forma más abierta, a veces presentan huellas de quema en sus paredes exteriores. Sirvieron posiblemente para 


\begin{tabular}{|l|c|c|c|}
\hline \multicolumn{1}{|c|}{ Tipo de objeto } & $\begin{array}{c}\text { Contexto primario } \\
\text { de depositación(Piso 2) }\end{array}$ & $\begin{array}{c}\text { Capas superficiales y } \\
\text { Piso 1 }\end{array}$ & Total \\
\hline Ollas domésticas & 53 & 148 & 420 \\
\hline Cántaros domésticos & 118 & 302 & 105 \\
\hline Vasijas de almacenaje & 33 & 72 & 686 \\
\hline Vasijas rituales (finas/decoradas) & 173 & 513 & 330 \\
\hline Figurinas & 104 & 226 & 230 \\
\hline Instrumentos musicales & 51 & 179 & 20 \\
\hline Pendientes & 2 & 18 & 201 \\
\hline
\end{tabular}

Tabla 2. Distribución de los objetos fabricados por ceramistas especializados en un conjunto arquitectónico del sector urbano del sitio Huacas de Moche. ${ }^{2}$ Han sido considerados sólo los pendientes completos, las figurinas e instrumentos musicales completos o semicompletos, así como los tiestos suficientemente grandes y diagnósticos para determinar el tipo morfológico de la vasija y realizar su reconstrucción.

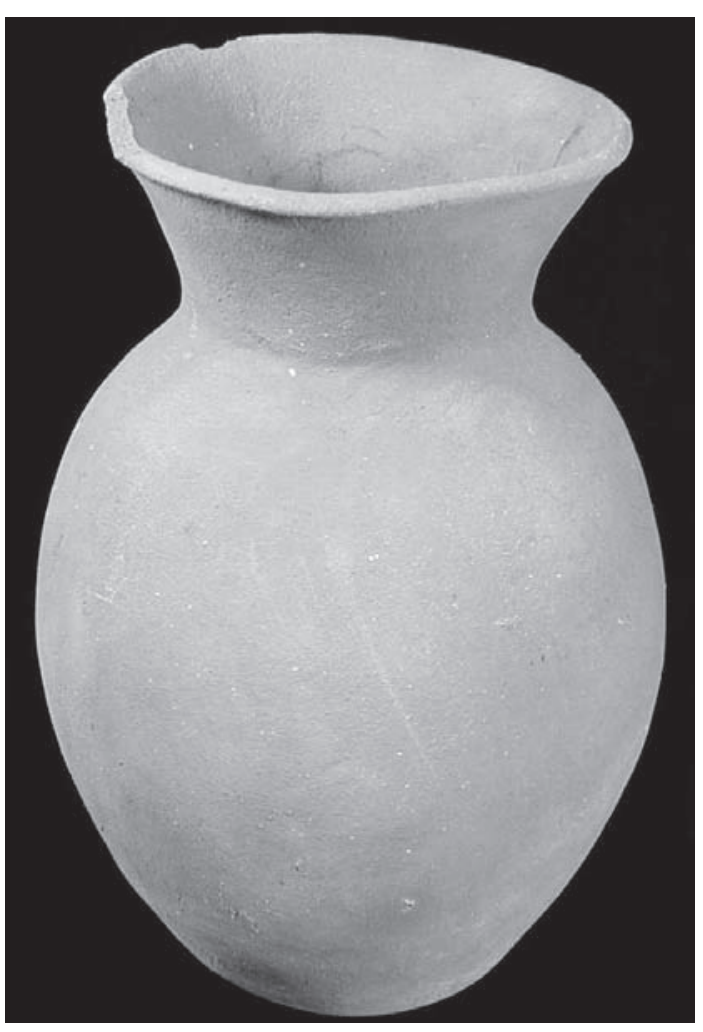

Figura 7. Cántaro doméstico mochica. Fotografía de Claude Chapdelaine.

hervir y fermentar chicha, como lo hacen actualmente los lugareños con cerámicas similares en la costa norte de Perú (Bankes 1985).

Las vasijas utilitarias mochica tuvieron probablemente una vida corta, especialmente aquellas que eran constantemente puestas al fuego y movidas con frecuencia. La gran cantidad de tiestos abandonados en contextos habitacionales demuestra el uso masivo y la alta demanda de ollas, cántaros y tinajas. No se han encontrado vasijas utilitarias in situ en tumbas o al interior de la arquitectura monumental del sitio Huacas de Moche. Aunque se habría consumido chicha y comida en las plazas y plataformas de Huaca de la Luna, lo más probable es que estos alimentos fueran preparados en las cocinas de los conjuntos arquitectónicos cercanos. De hecho, las vasijas utilitarias representan un importante porcentaje de la cerámica registrada en todos los sectores domésticos del sitio, incluyendo tanto recipientes completos como fragmentados (Tabla 2). Estas vasijas - debido a sus grandes proporciones y elevado peso- eran artículos difíciles de transportar, y con toda seguridad estaban destinadas a ser empleadas casi exclusivamente por la población local.

\section{Cerámica fina o ritual}

Generalmente moldeadas, las vasijas de cerámica fina presentan formas más variadas que la cerámica utilitaria, y son más pequeñas y delicadas, hechas con una pasta más fina. Los principales tipos morfológicos de vasijas rituales son los cántaros, las botellas (de asa lateral o estribo), los "floreros" (vasijas abiertas, anchas

\footnotetext{
2 Ejemplo del conjunto arquitectónico 37 (Figura 3). Este conjunto, excavado durante la temporada 2000 , mide $280 \mathrm{~m}^{2}$ y se ubica $1.5 \mathrm{~m}$ bajo la superficie actual del sitio.
} 


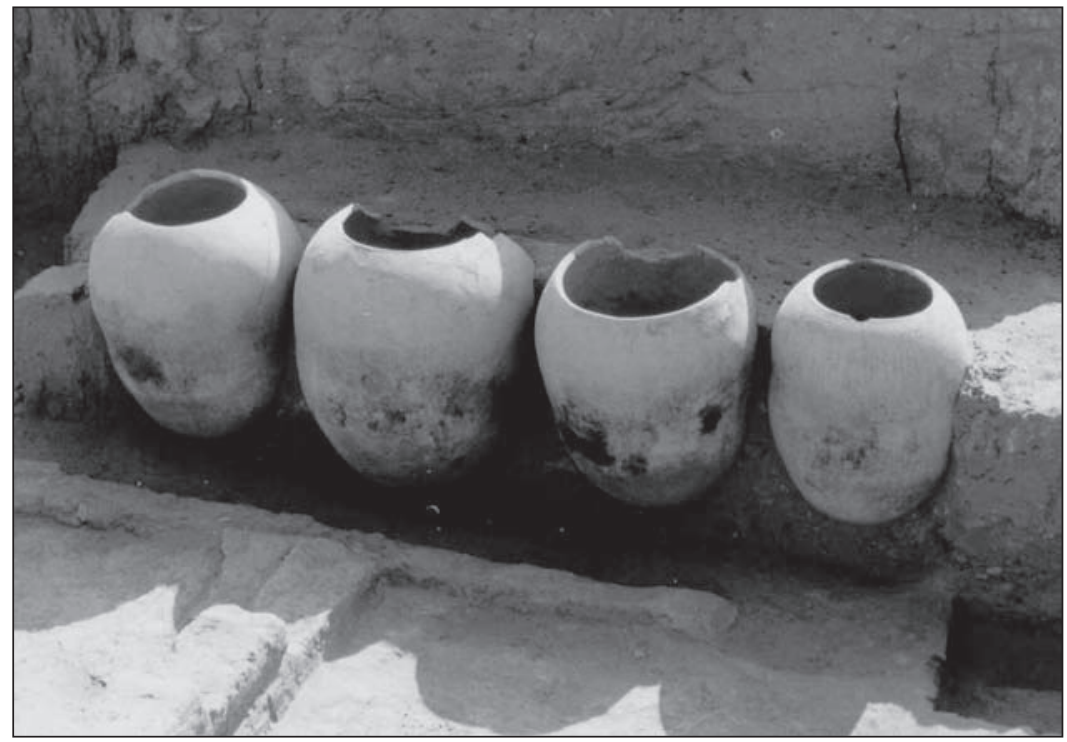

Figura 8. Tinajas de almacenaje in situ en el sector urbano de Huacas de Moche. Fotografía de la autora.

de boca), los cuencos (con o sin cuello), los cancheros (vasijas de forma lenticular, con mango) y los crisoles. Las vasijas de mayor calidad se caracterizan por los conocimientos artísticos y técnicos invertidos en su elaboración y decoración, así como por el simbolismo que transmiten. Las vasijas rituales llevan decoración escultórica o pindada, geométrica o figurativa. El mensaje simbólico expresado por las vasijas decoradas puede tomar forma de escenas iconográficas pintadas sobre el cuerpo, compuestas por elementos inspirados por el medio natural en el cual vivieron los mochicas y por su universo ideológico (Figura 9). Estos elementos son seres humanos, animales, plantas, objetos, criaturas híbridas o sobrenaturales, formando secuencias narrativas complejas. En otros casos, el mensaje ideológico está compuesto por un solo elemento representado de manera tridimensional.

Estas vasijas de cerámica fina, denominadas "rituales", se encuentran en gran cantidad en los sectores domésticos del sitio Huacas de Moche (ver Tabla 2), así como en contextos funerarios, y constituían el tipo más común de ofrenda mortuoria para la población mochica. Se encuentran en casi cada tumba excavada, de las más modestas a las más prestigiosas. Accesibles a toda la población urbana, en cantidades y calidades variables según el estatus socioeconómico de los individuos, eran el medio de integración por excelencia de los difuntos al sistema cultural e ideológico mochica. Expresaban la identidad social del muerto, así como sus creencias y las de sus semejantes en relación con la muerte.

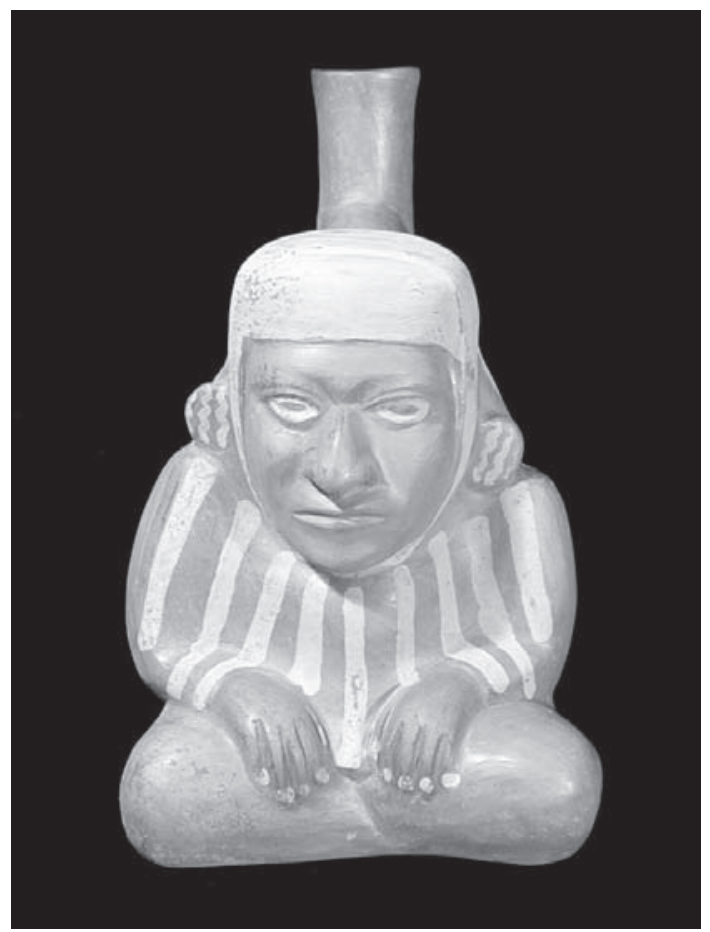

Figura 9. Vasija ritual pintada mochica proveniente de una tumba del sector urbano de Huacas de Moche. Fotografía de la autora. 


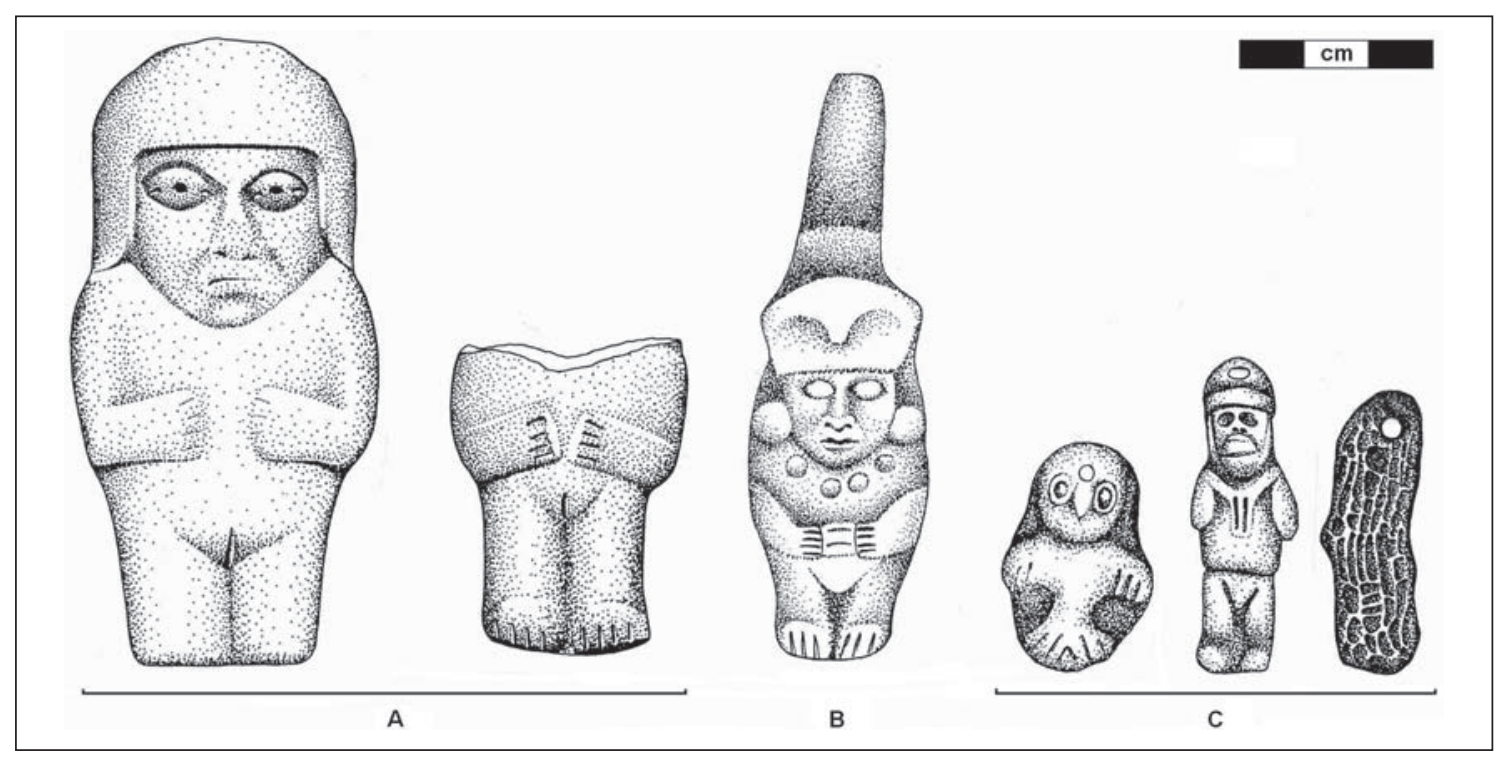

Figura 10. Objetos de cerámica fina provenientes del sector urbano de Huacas de Moche: a) figurinas femeninas; b) silbato; c) pendientes en forma de búho, esqueleto y maní. Dibujos de la autora, Hernando Malca y Fernando Moncada.

Las vasijas rituales no eran usadas sólo como ofrendas funerarias, sino también fueron utensilios de la vida cotidiana. Muchas llevan huellas de uso o fueron reparadas para prolongar su vida (Mogrovejo 1996). Solamente un pequeño porcentaje de las vasijas decoradas era finalmente dispuesto en entierros y tumbas, y en su mayoría no eran producidas para uso funerario, sino para ser empleadas diariamente por la gente. La mayor parte de estas piezas era quebrada accidentalmente durante su uso cotidiano, ocurriendo luego el descarte de los fragmentos (Donnan y McClelland 1999). Por otro lado, muchas de las vasijas encontradas en tumbas tienen huellas de abrasión o exhiben fracturas y despostillamientos producto del uso anterior a su uso como ofrendas mortuorias.

Una alta cantidad de vasijas decoradas ha sido documentada en cada una de las viviendas excavadas en Huacas de Moche y en otros sitios urbanos mochica, como Guadalupito en el valle de Santa. Por ejemplo, 179 vasijas pintadas o moldeadas, decoradas con diseños geométricos o figurativos, provienen de contextos primarios de depositación en el conjunto arquitectónico 37 de Huacas de Moche. A diferencia de la cerámica utilitaria, pocas vasijas decoradas proceden de los espacios dedicados a actividades de cocina y almacenamiento dentro de este conjunto, estando presentes, por el contrario, en el patio interior con banquetas, un espacio dedicado a las actividades cívicas y rituales de los residentes. Los fragmentos decorados eran particularmente abundantes en el amplio patio exterior, dónde también se han encontrado tinajas de almacenaje y más de 4000 fragmentos de huesos de camélidos. Todo indica que las vasijas decoradas eran elementos importantes en la vida cotidiana mochica, empleándose en comidas especiales o durante los festines organizados por los líderes de grupos familiares o corporativos, permitiendo a cada grupo demostrar su identidad, estatus y riqueza.

Las figurinas, los instrumentos musicales y los adornos corporales eran también objetos de cerámica fina producidos y usados por los ciudadanos de Huacas de Moche (Figura 10, Tabla 2). Las figurinas femeninas se encuentran en cada vivienda excavada, completas o fracturadas entre la cabeza y el cuerpo. Eran probablemente usadas como amuletos durante rituales domésticos, o consideradas como objetos investidos con propiedades mágicas y protectoras vinculadas a la fertilidad humana o agrícola. Se encuentran generalmente en contextos de preparación o de almacenaje de comida y chicha (Limoges 1999). Quizás fueron 
también usadas en rituales de curandería, tal como las usan hoy en día los curanderos modernos en la costa norte de Perú (Joralemon y Sharon 1993).

Los instrumentos musicales tales como silbatos, sonajas, ocarinas, pututos $^{3}$ y trompetas tenían una fuerte connotación ritual. Por ejemplo, según Bourget (2001), el acto de silbar estaba vinculado a las nociones de sacrificio, de ofrendas humanas y de comunicación con los ancestros. En la iconografía mochica, las trompetas y los pututos son manipuladas por guerreros y sacerdotes durante actividades de combate, sacrificio y rituales de entierros (Desjardins 2000). Por consiguiente, la abundancia de los instrumentos musicales de cerámica encontrados en varias viviendas mochica fue inesperada. Silbatos, sonajas y trompetas fueron probablemente usados regularmente por los ciudadanos de Huacas de Moche tanto en contextos rituales como recreativos. Los ocupantes de la ciudad también hacían uso de pendientes hechos de cerámica moldeada, representando varios animales, plantas, objetos o seres sobrenaturales como, por ejemplo, búhos, pallares, maní, semillas, porras o esqueletos. Estos adornos figurativos, además de su valor estético, poseían una fuerte connotación simbólica, debido a que estaban estrechamente relacionados con el universo ideológico mochica y con sus cánones de representación artística (Bernier 1999).

El taller de cerámica fina encontrado en el valle de Chicama y los indicios de produción presentes en el valle de Santa indicarían que durante el apogeo mochica cada valle tenía su propia producción de cerámica. ${ }^{4} \mathrm{Al}$ igual que las vasijas domésticas, los objetos producidos en el taller de cerámica fina de Huacas de Moche estaban destinados en primer término al mercado

\footnotetext{
3 Los pututos mochica son copias funcionales, hechas en cerámica, de las trompetas fabricadas con un caracol marino (Strombus galeatus, Strombus peruvianus), usadas en varias sociedades andinas.

4 Algunas vasijas rituales producidas en el valle de Moche fueron exportadas a los territorios dominados por las élites provinciales, como lo demuestra un "florero" importado encontrado en Guadalupito, valle de Santa. Este "florero", registrado en un conjunto arquitectónico de alto estatus, fue fabricado con arcilla químicamente muy similar a la del valle de Moche (Kennedy y Chapdelaine $2004 \mathrm{Ms}$ ).
}

local. Los moldes y las piezas inconclusas presentan importantes similitudes con las vasijas, figurinas, instrumentos musicales y adornos encontrados en las viviendas del sitio. En algunos casos también ha sido posible determinar que algunos de esos artefactos fueron fabricados con moldes registrados en el taller de cerámica del sitio.

Las excavaciones realizadas en sitios rurales del valle medio de Moche demuestran que algunos grupos de agricultores viviendo afuera de los centros regionales, en particular los habitantes de Ciudad de Dios, también utilizaban vasijas decoradas, silbatos y figurinas similares a los encontrados en las viviendas de Huacas de Moche (Gumerman y Briceño 2003; Ringberg 2008). La ausencia de moldes en Ciudad de Dios indica que estos objetos simbólicos eran producidos al exterior del poblado, pero será necesario recurrir a análisis de activación neutrónica para determinar si ellos fueron producidos en el taller de cerámica fina de Huacas de Moche.

\section{* Los contextos de la PROducción de Cerámica en Huacas de Moche}

\section{Una producción especializada}

En el Estado mochica sur las vasijas utilitarias y los objetos de cerámica fina eran producidos por artesanos especialistas. La producción especializada está atestiguada por indicios directos, como la presencia de talleres donde se encuentran concentraciones importantes de artefactos ligados a actividades artesanales (moldes, matrices, arcilla cruda, piezas no cocidas o con defectos de cocción). Por el contrario, excepto en los casos de algunas concentraciones de moldes hallados en ambientes de al macenaje en el sitio Huacas de Moche, estos indicios no se encuentran en las viviendas. Algunos ciudadanos de Huacas de Moche poseían moldes, pero la producción de objetos creados por medio de estos artefactos parece haber sido restringida. Mientras que objetos muy simples y con decoración sencilla, como cuentas, cucharas y ocarinas podían ser fabricados en las viviendas, mientras 
que los objetos simbólicos, como vasijas pintadas o con relieves, figurinas femeninas, silbatos-efigies y pendientes figurativos eran producidos en contextos distintos y claramente especializados.

Este tipo de producción también se encuentra atestiguado por indicios indirectos, especialmente en el caso de las grandes vasijas utilitarias, las que muestran un alto grado de estandarización formal (Mantha 1999), y su manufactura necesitaba una notable destreza técnica. Estudios etnográficos sobre la producción alfarera tradicional demuestran que el modelado y la cocción de vasijas de gran tamaño son operaciones complejas necesitando un conocimiento profundo de las arcillas, su composición y sus propiedades (Rice 1987; Shimada 1994b). En la fabricación de estas vasijas la etapa de cocción es el momento crucial de todo el proceso, el cual puede durar muchos días y aún llegar a causar fuertes pérdidas materiales si no está adecuadamente controlado (Shimada 1994b).

\section{Producción afiliada o independiente}

La zona urbana del sitio Huacas de Moche, excavada durante los últimos 15 años, proporciona datos importantes para el análisis de la producción especializada. Los datos arqueológicos provenientes de los contextos de producción y de consumo en Huacas de Moche parecen indicar que los ceramistas especializados que producían objetos simbólicos y rituales estaban afiliados a la élite, mientras que los productores de cerámica utilitaria trabajaban en un contexto más independiente.

En primer lugar, la localización de los talleres es uno de los principales criterios de distinción entre los especialistas afiliados y los independientes (Clark 1986; Costin 1991). El taller de cerámica ritual estaba ubicado cerca de una estructura monumental ocupada por la élite, la Huaca de la Luna, facilitando el control de la producción. También se encontraba del lado este de una calle ancha que separa los bloques arquitectónicos residenciales de estatus medio, localizados al oeste de los conjuntos de alto estatus, de uso ceremonial y ocupados por miembros de la élite, ubicados al este (ver Figura 3; Verano et al. 1999; Pimentel y Alvarez 2000; Chauchat y Gutiérrez 2004). El taller de cerámica utilitaria, por el contrario, estaba más alejado del sector urbano y de los conjuntos arquitectónicos de la élite.

La naturaleza de los bienes producidos en los talleres y la identidad de sus destinatarios nos informan igualmente sobre el grado de afiliación o de independencia de los artesanos. Los especialistas independientes, sujetos a una competencia en la adquisición de recursos alimenticios a cambio de bienes artesanales, tienden a favorecer comportamientos de economía y eficiencia en sus prácticas artesanales. Por el contrario, los indicios arqueológicos del consumo de la élite y de una producción de bienes de lujo, donde la fabricación implica una tecnología compleja, una inversión de energía importante y una gran experiencia artística son más susceptibles de indicar una especialización afiliada (Clark 1986).

Los objetos producidos en el taller de cerámica ritual no se encontraban entre los de más alto prestigio en la cultura material mochica, pero poseían un elevado valor simbólico expresado por su decoración y representaciones figurativas o por los contextos en los cuales fueron utilizados, tales como: el consumo de alimentos en circunstancias particulares, la ejecución de rituales domésticos y públicos, o la demostración de la pertenencia de sus usuarios a un grupo dominante. Estos objetos pueden ser calificados de "bienes de estatus intermediario" (Bernier 2008). Aunque se utilizaba arcilla local, los pigmentos blancos comprometidos en la decoración de las trompetas, las sonajas y las vasijas rituales provenían de la parte alta de los Andes norteños, ubicada al exterior del territorio mochica, dominada por distintos grupos étnicos como los Recuay, Huamachuco y Cajamarca. Estos pigmentos eran obtenidos a través de intercambios de larga distancia, y tanto su posesión como su posterior distribución eran controlados por las élites de Huacas de Moche. Varios ocupantes de la ciudad hacían uso de objetos de cerámica ritual: grupos familiares de estatus medio, especialistas rituales, líderes urbanos y miembros de la élite. 
Por el contrario, las vasijas producidas en el taller de cerámica doméstica poseían un valor estrictamente utilitario. Demostraban poco valor social o simbólico, y en el sitio de Huacas de Moche tampoco estaban presentes en los entierros como ofrendas funerarias. Generalmente estas piezas no eran decoradas ni pulidas, reflejando comportamientos de economía de energía y de tiempo típicos de la especialización independiente de los ceramistas. Las vasijas utilitarias vinculadas a la preparación de comida, eran utilizadas por toda la población y muy raramente se asocian a la arquitectura de la élite o a las actividades rituales. Toda la materia prima utilizada en el taller de cerámica doméstica estaba disponible muy cerca y en abundancia; su obtención difícilmente pudo haber sido restringida o controlada por la élite. La presencia de marcas de alfareros ${ }^{5}$ exclusivamente en las vasijas utilitarias también apoya la hipótesis de su producción por artesanos independientes. Estos se encontraban en situaciones de precariedad y de competencia para asegurar su subsistencia a partir de su trabajo artesanal. Tuvieron la necesidad de distinguirse y de identificarse como propietarios de las vasijas que fabricaron, en contraste con los artesanos afiliados que trabajaron bajo la autoridad de jefes que controlaban directamente la producción. La identificación de sus vasijas habría asegurado a los artesanos independientes el reconocimiento y la retribución por parte de los consumidores del producto de su trabajo (Bernier 2005). Aunque no es posible por ahora confirmar fehacientemente que las vasijas utilitarias mochica eran producidas por artesanos independientes (Gamarra y Gayoso 2008), no parece existir ningún indicio del control de su elaboración por parte de los grupos de élite.

\section{La organización de la producción afiliada}

La categoría de "artesanos especialistas afiliados a la élite” es muy general. Varias categorías de élites, caracterizadas por distintos roles sociales y niveles de poder, estaban presentes en el Estado mochica sur y residían en Huacas de Moche, así como en centros

\footnotetext{
5 Para un análisis detallado de las marcas de alfareros Moche en el valle de Santa, ver Donnan (1971).
}

regionales dotados de arquitectura monumental. Los arqueólogos suponen que los miembros de la élite dirigente y los individuos de alto estatus asociados a ellos lideraban la jerarquía social. Este grupo de individuos (en sí mismo diversificado en su interior) mantenía su autoridad sobre la población y la mano de obra, la ideología oficial y los símbolos aprobados para expresarla (Bawden 1996).

Una categoría de "élite urbana", manteniendo una relación de autoridad más directa sobre los linajes y grupos corporativos de la población urbana del Estado mochica sur, ha sido documentada en Huacas de Moche y en varios centros regionales. La presencia de líderes urbanos está demostrada por varios datos arqueológicos como, por ejemplo, la gran variabilidad en las prácticas funerarias en los contextos urbanos (Millaire 2002; Tello et al.2003) y la diversa calidad de la arquitectura doméstica (Topic 1977; van Gijseghem 2001; Chapdelaine et al. $2003 \mathrm{Ms}$ ).

Los artesanos especialistas pudieron estar afiliados a la élite dirigente o a una categoría secundaria de élite, tal como aquella compuesta por los líderes urbanos. En el Estado mochica sur, parece que las dos situaciones existían simultáneamente. Las vasijas finas más prestigiosas, como los huaco-retratos y las botellas con escenas narrativas complejas delicadamente pintadas, podían haber sido producidas por especialistas estrechamente afiliados a la élite dirigente. Sin embargo, las vasijas prestigiosas y los moldes correspondientes son elementos raros, aunque presentes, en los talleres de Huacas de Moche y Cerro Mayal.

La producción de bienes intermediarios en estos dos talleres probablemente estaba controlada de manera directa por los líderes urbanos, quienes a su vez se hallaban bajo el mando de una autoridad superior. Estos bienes no estaban destinados exclusivamente a la élite dirigente, sino también a la población urbana, pues se encuentran en cada vivienda excavada. Además, el taller de cerámica fina de Huacas de Moche, ubicado en proximidad a la arquitectura monumental del sitio, también se sitúa cerca de varios conjuntos arquitectónicos de alto estatus del sector urbano del sitio. 
Los datos arqueológicos no permiten determinar con precisión cómo era supervisada y organizada la circulación de bienes intermediarios entre los grupos familiares mochica. Es poco probable que las vasijas finas, las figurinas, los instrumentos musicales y los ornamentos fueran en su totalidad recogidos, almacenados y redistribuidos por la élite dirigente. No se ha descubierto ninguna estructura de almacenaje a gran escala asociada a la arquitectura pública o monumental en Huacas de Moche, y la plaza principal de Huaca de la Luna, aunque contando con zonas destinadas a encuentros sociales y presentaciones solemnes entre jerarcas, no contaba con ambientes de almacenaje a gran escala (Gamboa 2005, 2008). Mientras que una parte de la producción de vasijas finas podía destinarse a ser empleada como tributo para la élite dirigente, la mayoría de los bienes intermediarios estaba destinada al trueque o intercambio entre los grupos productores y familiares, bajo la supervisión de los líderes urbanos. Estos intercambios probablemente también implicaban el intercambio de comida, chicha, bienes materiales complementarios, servicios o alianzas. La producción de grandes cantidades de chicha era posible en las viviendas de los propios productores y consumidores de bienes intermediarios en Huacas de Moche. Fogones, metates, ollas y vasijas de almacenaje de líquidos se encuentran en cada conjunto doméstico del sitio, también en cercanía a los talleres donde se creaban productos complementarios como objetos de cobre y adornos de piedra (Chapdelaine 1997; Chiguala et al. 2004, 2006; Bernier 2006).

\section{- Los fundamentos de la PROducción DE CERÁMICA MOCHICA}

Mientras que los talleres aportan información sobre la organización de la producción de cerámica, las estructuras habitacionales, así como los conjuntos funerarios excavados, informan sobre los contextos de uso de los bienes materiales y, eventualmente, sobre los fundamentos de la producción artesanal.

Sin duda, la producción especializada de cerámica tuvo un impacto en la esfera económica mochica. En
Huacas de Moche ningún grupo familiar parece haber sido completamente autónomo en lo que concierne a la producción de vasijas, figurinas e instrumentos musicales. Las ventajas económicas de la producción especializada están ligadas a la eficacia y a la productividad del trabajo de los ceramistas. La especialización permite producir más objetos y de mejor calidad con una menor inversión de tiempo y de energías (Evans 1978; Hagstrum 1985). Entonces, las ventajas económicas de la especialización artesanal deberían notarse más en el caso de la cerámica utilitaria, apreciada por sus cualidades técnicas y cuyo valor no disminuye por los comportamientos de la economía durante la producción. Las vasijas utilitarias tales como ollas, cántaros y tinajas eran utilizadas a gran escala en las viviendas urbanas mochica. Su fabricación estaba fuertemente favorecida por el conocimiento de los procesos tecnológicos adecuados, por la experiencia de los alfareros y por una competencia transmitida entre especialistas trabajando en el mismo lugar.

Desde un punto de vista económico, la producción especializada también puede ser ventajosa en el caso de los bienes con alto valor material y simbólico, pues el contexto de especialización y uso de moldes aumenta la eficacia en la producción y el apego a los estándares estilísticos. De hecho, los contextos arqueológicos en centros urbanos de los valles de Moche y Santa indican que algunos bienes simbólicos, especialmente las vasijas finas con decoración sencilla y las figurinas femeninas, eran fabricados a gran escala. Sin embargo, los ceramistas Mochica no siempre aprovecharon el potencial económico de la producción en serie, como parece haber ocurrido en el caso de la elaboración de cerámica fina. Por ejemplo, a pesar de que numerosas vasijas idénticas podían ser producidas con el mismo molde, los ceramistas limitaban la cantidad de su producción, e invertían tiempo adicional para añadir detalles modelados o pintados a los productos finales. Las diversas vasijas retrato de un mismo personaje nunca fueron del todo idénticas, dado que los artesanos laboriosamente añadían diferentes adornos, tocados y motivos pintados (Donnan 2001), de manera que las ventajas económicas de la producción especializada no parecen haber estado completamente ligadas a la fabricación de las vasijas decoradas. 
La cerámica decorada, dotada de un fuerte simbolismo y de un valor ritual además de material, desempeña generalmente un papel importante dentro del uso de la producción especializada con fines políticos (Hayden 1995, 1998). En el sitio Huacas de Moche, los líderes urbanos que manejaban la fabricación de bienes intermediarios aprovechaban su acceso privilegiado a esos símbolos materiales para elaborar sus propias estrategias políticas. Los grupos familiares del sector urbano de Huacas de Moche tenían relaciones de intercambios, deudas, reciprocidad y competencia entre ellos (van Gijseghem 2001). Como medios de expresión de la ideología mochica, los objetos de cerámica fina desempeñaron un papel importante en las estrategias políticas en el ámbito familiar, insertándose en los mecanismos de creación de identidades y en las maniobras destinadas a subir de posición social. Los líderes urbanos podían mejorar su estatus sociopolítico a través de la producción, posesión, manipulación y distribución de objetos simbólicos. Como hemos visto, las vasijas decoradas y los instrumentos musicales eran parte esencial de los festines competitivos y otros rituales que acompañaban cada nacimiento, ritual de pasaje y ceremonia fúnebre, ocasiones donde estos artículos eran exhibidos u ofrecidos. De manera similar, las figurinas femeninas probablemente eran utilizadas como amuletos durante rituales domésticos y sesiones de curanderismo. A su vez, los pendientes de cerámica imitaban los adornos suntuosos creados en materiales menos accesibles y llevados por los miembros de la élite dirigente.

Los líderes urbanos de Huacas de Moche no eran el único estrato jerárquico que aprovechaba el control de la producción de cerámica fina. La élite dirigente del sitio también se habría beneficiado de la producción de cerámica simbólica, usándola estratégicamente tanto para mantener el funcionamiento del sistema social que ellos mismos dirigían como para expresar y consolidar su poder y legitimar su autoridad. El uso selectivo de los bienes materiales simbólicos y el control de su producción con fines políticos no estaba limitado a la cerámica fina en el sitio Huacas de Moche. Varios talleres de metalurgia y de talla de ornamentos de piedra existían en la zona urbana del sitio y estaban dirigidos por líderes urbanos o, en el caso de la metalurgia, por la élite dirigente (Uceda y Rengifo 2006; Bernier 2008; Rengifo y Rojas 2008).

Los centros urbanos mochica albergaban una gran cantidad de trabajadores integrados al sistema político, los mismos que aseguraban el funcionamiento y la continuidad de la estructura estatal y soportaban el prestigio de su élite. Favoreciendo el acceso de los trabajadores a la cerámica simbólica con la cual ellos podían identificarse, la élite dirigente reforzaba el sentimiento de pertenencia del pueblo al sistema, al mismo tiempo que gozaba del beneficio de su trabajo. La élite mochica tenía también interés en usar la cerámica decorada de alto estatus para demostrar oficialmente la autoridad que poseía por medio de rituales públicos, ceremonias funerarias u otras manifestaciones ostentosas de poder. La cerámica prestigiosa y simbólica era esencial dentro de la estrategia de legitimación de la autoridad. Efectivamente, el poder de la élite dirigente y la jerarquía social institucionalizada estaban asociados a restricciones de la libertad y del acceso a los recursos de una gran parte de la población. Al manipular la ideología oficial con fines políticos, la élite podía hacer demostración de su autoridad y de la desigualdad social como parte de la vida normal frente a los ojos de los grupos subordinados (Cross 1993; Bawden 1996). La ideología estatal puede ser un medio privilegiado de legitimación si ésta es eficazmente difundida. En tiempos mochica este proceso era posible mediante el uso de símbolos materiales como, por ejemplo, las vasijas decoradas con escenas iconográficas complejas (Bawden 1996; DeMarrais et al. 1996).

Los objetos simbólicos producidos por los artesanos especialistas afiliados a la élite desempeñaron un papel no sólo en el mantenimiento del sistema social mochica, sino también en el desarrollo del Estado. Recientemente se ha discutido el rol de la producción especializada controlada por la élite en el desarrollo de la complejidad social y de los sistemas políticos. Los bienes simbólicos o prestigiosos permiten a los líderes emergentes y a la élite atraer aliados, crear alianzas, establecer identidades étnicas, aumentar la desigualdad social y gradualmente legitimizarla, así como aumentar 
el ámbito y amplitud de su autoridad (Inomata 2001; Vaughn 2006). En la costa norte prehispánica de Perú, aunque el militarismo probablemente tuvo un impacto importante en la formación del Estado (Shimada 1987; Wilson 1988), las investigaciones recientes en el valle de Santa indican que la incorporación de este valle al territorio mochica fue realizada en gran parte a través de la intensificación y reordenamiento de las relaciones económicas interzonales, así como por medio de la manipulación ideológica (Chapdelaine et al.2003 Ms).

Los ceramistas especializados y el producto de su trabajo, especialmente las vasijas de cerámica fina, ejercieron una gran influencia sobre el desarrollo y la expansión territorial del sistema político mochica sur. El uso de imágenes y símbolos visuales fue una estrategia esencial en este proceso diplómatico, y las imágenes difundidas desde los centros productores debieron ser elegidas cuidadosamente por los agentes del Estado. De hecho, la élite local mochica transplantada al valle de Santa, primero importó vasijas finas con motivos decorativos expresando la ideología dominante, empleándolas como bienes suntuarios y ofrendas funerarias (Chapdelaine et al. 2005), y luego estimuló la producción local de tales objetos simbólicos.

\section{* Conclusión}

La producción de cerámica utilitaria y ritual era una actividad especializada en la sociedad mochica. Se conocen varios lugares de producción de cerámica en el territorio mochica sur. En los talleres de cerámica fina de Huacas de Moche y de Cerro Mayal se produjeron objetos decorados y simbólicos de uso generalmente ritual, accesibles a la población urbana y posiblemente también a la rural que, además, eran empleados por la élite durante las ceremonias públicas. En el taller de cerámica utilitaria de Huacas de Moche se produjeron vasijas necesarias para la vida cotidiana. La organización del trabajo de los ceramistas especializados variaba según el tipo de objeto producido. La cerámica ritual era producida por artesanos especializados afiliados a varias categorías de élites, mientras que las vasijas utilitarias eran fabricadas por alfareros independientes, lo cual favorecía comportamientos eficientes en el trabajo y control del gasto económico de cada grupo de productores.

La producción especializada de cerámica utilitaria tuvo un impacto económico en la vida diaria de la población mochica. Varios bienes intermediarios creados en los talleres de Huacas de Moche y Cerro Mayal, tales como vasijas decoradas, figurinas, instrumentos musicales y ornamentos, eran usados por los líderes urbanos en las estrategias dirigidas al aumento de sus propios estatus y autoridad. La producción especializada de cerámica ritual también proporcionaba ventajas políticas importantes a los líderes sociopolíticos. La élite dirigente mochica aprovechaba el trabajo de los artesanos especialistas y la producción de cerámica fina y simbólica, para facilitar tanto la integración social de la comunidad como la comunicación y la consolidación de su poder, empleando las vasijas y su simbolismo en las estrategias diplomáticas de conquista territorial puestas en práctica en aquellos tiempos en la costa norte peruana.

Agradecimientos Deseo agradecer primero al Dr. Claude Chapdelaine, que me dio la oportunidad de participar en el proyecto ZUM (Zona Urbana Moche) bajo su dirección, por su constante apoyo y generosidad, y por su gran ayuda académica y técnica. Los datos usados para realizar este artículo provienen del proyecto ZUM y del Proyecto Huaca de la Luna dirigido por Santiago Uceda y Ricardo Morales de la Universidad Nacional de Trujillo. Agradezco también a la Dra. Norma Ratto y a la Dra. Verónica Williams por la oportunidad de participar en el simposio "Historia y prácticas sociales. Aportes de la cerámica arqueológica", en el marco del $52^{\circ}$ Congreso Internacional de Americanistas. Muchas gracias a los consultores externos que criticaron el manuscrito original y proporcionaron consejos valiosos y útiles. Finalmente, gracias a Elisenda Vila Llonch y Jorge Gamboa por la revisión del español. 


\section{* Referencias citadas}

ARMAS, J., 1998. Investigaciones arqueológicas en talleres alfareros de la sociedad Moche, complejo arqueológico Huacas del Sol y de la Luna, Valle de Moche. Tesis de Licenciatura en Arqueología, Universidad Nacional la Libertad, Trujillo.

BANKES, G., 1985. The manufacture and circulation of paddle and anvil pottery on the north coast of Peru. World Archaeology $17(2): 269-277$

Bawden, G., 1996. The Moche. Blackwell Publishers, Oxford.

Bernier, H., 1999. L'usage de la parure corporelle dans la culture Moche du Pérou précolombien et le cas du site Moche, capitale urbaine. Tesis de Maestría, Departamento de Antropología, Université de Montréal, Montreal.

2005. Étude archéologique de la production artisanale au site Huacas de Moche, côte nord du Pérou. Tesis de Doctorado, Departamento de Antropología, Université de Montréal, Montreal.

2006. Excavaciones en el conjunto arquitectónico 37, centro urbano Moche. En Investigaciones en la Huaca de la Luna 2000, S. Uceda, E. Mujica y R. Morales (Eds.), pp. 185-215. Facultad de Ciencias Sociales, Universidad Nacional la Libertad, Trujillo.

2008. La especialización artesanal en el sitio Huacas de Moche: Contextos de producción y función sociopolítica. En Arqueología mochica, nuevos enfoques. Actas del Primer Congreso Internacional de Jóvenes Investigadores de la Cultura Mochica, L. J. Castillo, H. Bernier, G. Lockard y J. Rucabado (Eds.), pp. 33-51. Instituto Francés de Estudios Andinos y Pontificia Universidad Católica del Perú, Lima.

Billman, B., 2002. Irrigation and the origins of the southern Moche State on the north coast of Peru. Latin American Antiquity 13 (4):371-400.

Bourget, S., 2001. Children and ancestors: Ritual practices at the Moche site of Huaca de la Luna, north cosat of Peru. En Ritual sacrifice in Ancient Peru. New discoveries and interpretations, E. Benson y A. Cook (Eds.), pp. 93-118. University of Texas Press, Austin.

Brumfiel, E. y T. Earle, 1987. Specialization, exchange and complex societies: An introduction. En Specialization, exchange and complex societies, E. Brumfiel y T. Earle (Eds.), pp. 1-9. New Directions in Archaeology, Cambridge University Press, Cambridge.

Castillo, L. J. y C. Donnan, 1994. Los mochica del norte y los mochica del sur. En Vicús, K. Makowski, C. Donnan, I. A. Bullon, L. J. Castillo, M. Diez-Canseco, O. Elespuru y J. A. Murro (Eds), pp. 143-178. Banco de Crédito de Perú, Lima.
CAstillo, L. J. y S. UCEDA, 2008. Los mochicas. En Handbook of South American archaeology, H. Silverman y W. Isbell (Eds.), pp. 707-729. Springer, Nueva York.

Chapdelaine, C., 1997. Le tissu urbain du site Moche. En À l'ombre du Cerro Blanco: Nouvelles découvertes sur la culture Moche, côte nord du Pérou, C. Chapdelaine (Ed.), pp. 11-81. Les cahiers d'anthropologie 1, Université de Montréal, Montreal.

1998. Excavaciones en la zona urbana de Moche durante 1996. En Investigaciones en la Huaca de la Luna 1996, S. Uceda, E. Mujica y R. Morales (Eds.), pp. 85-115. Facultad de Ciencias Sociales, Universidad Nacional la Libertad, Trujillo.

2000. Struggling for survival. The urban class of the Moche site, north coast of Peru. En Environmental disaster and the archaeology of human response, G. Bawden y R. Reycraft (Eds.), pp. 121-142. Maxwell Museum of Anthropology, Anthropological Papers 7, Albuquerque.

2001. The growing power of a Moche urban class. En Moche art and archaeology in Ancient Peru, J. Pillsbury (Ed.), pp. 69-87. Studies in the History of Art 63, Center for Advanced Study in the Visual Arts, Symposium Papers XL, National Gallery of Art of Washington, Yale University Press, New Haven y Londres.

2002. Out in the streets of Moche: Urbanism and sociopolitical organization at a Moche IV urban center. En Andean archaeology I. Variations in sociopolitical organization, W. Isbell y H. Silverman (Eds.), pp. 53-88. Kluwer Academic/Plenium Publishers, Nueva York.

2003. La ciudad de Moche: Urbanismo y Estado. En Moche: Hacia el final del milenio. Actas del Segundo Coloquio sobre la Cultura Moche, vol. 2, S. Uceda y E. Mujica (Eds.), pp. 247-285. Universidad Nacional de Trujillo y Pontificia Universidad Católica del Perú, Lima.

Chapdelaine, C. y V. Pimentel, 2001 Ms. La presencia Moche en el valle del Santa, Costa Norte de Perú. Informe del proyecto arqueológico PSUM (Proyecto Santa de la Universidad de Montreal), junio-agosto de 2000 .

Chapdelaine, C., G. Kennedy y S. UCeda, 1995. Activación neutrónica en el estudio de la producción local de cerámica ritual en el sitio Moche, Perú. Bulletin de l'Institut Français d'Études Andines 24 (2): 183-212.

2001. Neutron activation analysis of metal artifacts from the Moche site, North Coast of Peru. Archaeometry 43 (3): 373-391. 
Chapdelaine, C., H. Bernier y V. Pimentel, 2003. Investigaciones en la zona urbana Moche, temporada 1998 y 1999. En Investigaciones en la Huaca de la Luna 1998-1999, S. Uceda, E. Mujica y R. Morales (Eds.), pp. 119-197. Facultad de Ciencias Sociales, Universidad Nacional la Libertad, Trujillo.

Chapdelaine, C., V. Pimentel y H. Bernier, 2003 Ms. La presencia Moche en el valle de Santa, Costa Norte de Perú. Informe del proyecto arqueológico PSUM (Proyecto Santa de la Universidad de Montreal), mayo-agosto de 2002.

Chapdelaine, C., V. Pimentel y J. Gamboa, 2005. Entierros Moche en el sitio El Castillo de Santa. Una primera aproximación. En Corriente arqueológica 1. Muerte y evidencias funerarias en los Andes Centrales: Avances y perspectivas, C. Olaya y M. Romero (Eds.), pp. 13-41. Actas del Tercer Seminario de Arqueología de la Universidad Federico Villarreal, Lima.

Chauchat, C. y B. Gutiérrez, 2004. Excavaciones en la Plataforma Uhle. En Proyecto arqueológico Huaca de la Luna, informe técnico 2003, S. Uceda y R. Morales (Eds.), pp. 53-82. Facultad de Ciencias Sociales, Universidad Nacional la Libertad, Trujillo.

Chiguala, J., N. Gamarra, H. Gayoso, O. Prieto, C. Rengifo y C. RoJAS, 2004. Dinámica ocupacional del conjunto arquitectónico 27, núcleo urbano del complejo arqueológico Huacas del Sol y de la Luna. En Proyecto arqueológico Huaca de la Luna, informe técnico 2003, S. Uceda y R. Morales (Eds.), pp. 83150. Facultad de Ciencias Sociales, Universidad Nacional la Libertad, Trujillo.

Chiguala, J., C. Almonacid, M. Orbegoso, D. Rojas, y M. Sandoval, 2006. La integración funcional de los conjuntos arquitectónicos 17 y 35 como parte de un bloque arquitectónico en el núcleo urbano. En Proyecto arqueológico Huaca de la Luna, informe técnico 2005, S. Uceda y R. Morales (Eds.), pp. 137206. Facultad de Ciencias Sociales, Universidad Nacional la Libertad, Trujillo.

Childe, V. G., 1950. The urban revolution. Town Planning Review $21(1): 3-17$.

CLARK, J. E., 1986. From mountains to molehills: A critical review of Teotihuacan's obsidian industry. Research in Economic Anthropology, suplemento 2: 23-74.

1995. Craft specialization as an archaeological category. Research in Economic Anthropology 16: 267-294.

Clark, J. E. y W. J. Parry, 1990. Craft specialization and cultural complexity. Research in Economic Anthropology 12:289-346.
Costin, C. L., 1991. Craft specialization: Issues in defining, documenting, and explaining the organization of production. Journal of Archaeological Method and Theory 3: 1-56.

Costin, C. L. y M. B. Hagstrum, 1995. Standardization, labor investment, skill and the organization of ceramic production in late prehispanic highland Peru. American Antiquity $60(4): 619-639$.

Costin, C. L. y R. P. Wright (Eds.), 1998. Craft and social identity. Archaeological Papers of the American Anthropological Association 8, Washington D. C.

Cross, J. R., 1993. Craft production in nonstratified societies. Research in Economic Anthropology 14: 61-84.

Demarrais, E., L. J. Castillo y T. K. Earle, 1996. Ideology, materialization, and power strategies. Current Anthropology 37 (1):15-31.

Desjardins, B., 2000. La place des musiciens dans le quotidien et le cérémonial d'une société complexe, la culture Moche de la côte nord du Pérou précolombien. Tesis de Maestría, Departamento de Antropología, Université de Montréal, Montreal.

Donnan, C., 1971. Ancient Peruvian potter's marks and their interpretation through ethnographic analogy. American Antiquity 36 (4): 460-465.

2001. Moche ceramic portraits. En Moche art and archaeology in Ancient Peru, J. Pillsbury (Ed.), pp. 127-139. Studies in History of Art 63, Center for Advanced Study in the Visual Arts, Symposium Papers XL, National Gallery of Art of Washington, Yale University Press, New Haven y Londres.

Donnan, C. y C. Mackey, 1978. Ancient burial patterns of the Moche Valley, Peru. University of Texas Press, Austin.

Donnan, C. y D. McClelland, 1999. Moche fineline painting. Its evolution and its artists. UCLA Fowler Museum of Cultural History, Los Angeles.

Evans, R., 1978. Early craft specialization: An example from the Balkan chalcolithic. En Social archaeology, beyond subsistence and dating, C. L. Redman (Ed.), pp. 113-129. Academic Press, Nueva York.

GAMARRA, N.y H. GAYOSO, 2008. La cerámica doméstica en Huacas de Moche: Un intento de tipología y seriación. En Arqueología mochica, nuevos enfoques. Actas del Primer Congreso Internacional de Jóvenes Investigadores de la Cultura Mochica, L. J. Castillo, H. Bernier, G. Lockard y J. Rucabado (Eds.), pp. 187-202. Instituto Francés de Estudios Andinos y Pontificia Universidad Católica del Perú, Lima. 
GambOA, J., 2005. Continuidad y cambio en la organización de los espacios arquitectónicos de Huaca de la Luna y Plataforma A de Galindo, Costa Norte de Perú. Boletín del Instituto Francés de Estudios Andinos 34: 161-183.

2008. Plazas y cercaduras: Una aproximación a la arquitectura pública Moche IV y V en los valles de Moche y Santa. En Arqueología mochica, nuevos enfoques. Actas del Primer Congreso Internacional de Jóvenes Investigadores de la Cultura Mochica, L. J. Castillo, H. Bernier, G. Lockard y J. Rucabado (Eds.), pp. 203-2 17. Instituto Francés de Estudios Andinos y Pontificia Universidad Católica del Perú, Lima.

Gero, J., 1983. Material culture and the reproduction of social complexity: A lithic example from the Peruvian Formative. Tesis de Doctorado, University of Massachusetts, Amherst.

Gumerman, G.y J. Briceño, 2003. Santa Rosa-Quirihuac y Ciudad de Dios: Asentamientos rurales en la parte media del valle de Moche. En Moche: Hacia el final del milenio. Actas del Segundo Coloquio sobre la Cultura Moche vol. 1, S. Uceda y E. Mujica (Eds.), 217-243. Universidad Nacional de Trujillo y Pontificia Universidad Católica del Perú, Lima.

Hagstrum, M., 1985. Measuring prehistoric ceramic craft specialization: A test case in the American Southwest. Journal of Field Archaeology 12: 65-75.

Hastings, M. y M. Moseley, 1975. The adobes of Huaca del Sol and Huaca de la Luna.American Antiquity 40: 196-203.

Hayden, B., 1995. The emergence of prestige technologies and pottery. En The emergence of pottery. Technology and innovation in ancient societies, W. Barnett y J. Hoopes (Eds.), pp. 257-264. Smithsonian Institution Press, Washington D. C. y Londres.

1998. Practical and prestige technologies: The evolution of material systems. Journal of Archaeological Method and Theory 5(1): 1-55.

Helms, M., 1993. Craft and the kingly ideal. University of Texas Press, Austin.

Henrickson, E. y M. McDonald, 1983. Ceramic form and function: An ethnographic search and an archaeological application. American Anthropologist 85:630-643.

INOMATA, T., 2001. The power and ideology of artistic creation. Current Anthropology 42:321-350.

JarA, G., 2000. Producción de vasijas domésticas en un taller alfarero Moche en la falda noreste de cerro Blanco, valle de Moche. Tesis de Licenciatura en Arqueología, Universidad Nacional la Libertad, Trujillo.
Joralemon, D.y D. SHARON, 1993. Sorcery and shamanism: Curanderos and clients in Northern Peru. University of Utah Press, Salt Lake City.

JUNKER, L., 1999. Raiding, trading, and feasting. The political economy of Philippine chiefdoms. University of Hawaii Press, Honolulu.

Kaulicke, P., 1998. Max Uhle y el Perú antiguo. Pontificia Universidad Católica del Perú, Lima.

Kennedy, G. y C. Chapdelaine, 2004 Ms. Ponencia presentada en el Simposio "Southern Moche: Understanding the first expansionist State on the North Coast of Peru", $69^{\text {th }}$ Annual Meeting of the Society for American Archaeology, Montreal.

Limoges, S., 1999. Étude morpho-stylistique et contextuelle des figurines du site Moche, Pérou. Tesis de Maestría, Departamento de Antropología, Université de Montréal, Montreal.

Lumbreras, L., 1987. Examen y clasificación de la cerámica. Gaceta Andina 31.

Manrique, E. y J. CÁceres, 1989. Manual de registro y catalogación de cerámica precolombina. Consejo Nacional de Ciencia y Tecnología, Lima.

Mantha, A., 1999. L'État Moche et la spécialisation du travail: Une comparaison de l'organisation de la production de céramiques domestiques et rituelles. Tesis de Maestría, Departamento de Antropología, Université de Montréal, Montreal.

Millaire, J. F., 2002. Moche burial patterns. An investigation into prehispanic social structure. BAR International Series 1066, Archaeopress, Oxford.

Mogrovejo, J., 1996. Análisis de las funciones de la cerámica ritual mochica. Revista del Museo de Arqueología, Antropología e Historia 6:123-136.

Moseley, M., 1992. The Incas and their ancestors. Thames and Hudson, Londres.

Muller, J., 1984. Mississippian specialization and salt. American Antiquity 49 (3): 489-507.

Peebles, C.y S. Kus, 1977. Some archaeological correlates of ranked societies. American Antiquity 42: 421-448.

Pimentel, V. y G. Álvarez, 2000. Relieves policromos en la plataforma funeraria Uhle. En Proyecto arqueológico Huaca de la Luna, informe técnico 2000, S. Uceda y R. Morales (Eds.), pp. 181-203. Facultad de Ciencias Sociales, Universidad Nacional la Libertad, Trujillo. 
RengiFo, C.y C. RojAS, 2008. Talleres especializados en el conjunto arqueológico Huacas de Moche: El carácter de los especialistas y de su producción. En Arqueología mochica, nuevos enfoques. Actas del Primer Congreso Internacional de Jóvenes Investigadores de la Cultura Mochica, L. J. Castillo, H. Bernier, G. Lockard y J. Rucabado (Eds.), pp.325-339. IFEA y Pontificia Universidad Católica del Perú, Lima.

Rice, P., 1987. Pottery analysis: A sourcebook. University of Chicago Press, Chicago.

RingberG, J. E., 2008. Figurines, household rituals, and the use of domestic space in a middle Moche rural community. En Arqueología mochica, nuevos enfoques. Actas del Primer Congreso Internacional de Jóvenes Investigadores de la Cultura Mochica, L. J. Castillo, H. Bernier, G. Lockard y J. Rucabado (Eds.), pp.341357. IFEA y Pontificia Universidad Católica del Perú, Lima.

Russel, G. y M. JACKSON, 2001. Political economy and patronage at Cerro Mayal, Peru. En Moche art and archaeology in Ancient Peru, J. Pillsbury (Ed.), pp. 159-175. Studies in the History of Art 63, Center for the Advanced Study in the Visual Arts, Symposium Papers XL, National Gallery of Art of Washington, Yale University Press, New Haven y Londres.

Russel, G., B. L. Leonard y J. Briceño, 1994. Producción de cerámica Moche en el valle de Chicama, Perú: El taller de Cerro Mayal. En Tecnología y organización de la producción de cerámica en los Andes, I. Shimada (Ed.), pp. 201-227. Pontificia Universidad Católica del Perú, Lima.

1998. The Cerro Mayal workshop: Addressing issues of craft specialization in Moche society. En Andean ceramics: Technology, organization, and approaches, I. Shimada (Ed.), pp. 63-89. MASCA Research Papers in Science and Technology, Suplemento de Applied Science Center for Archaeology vol. 15, University of Pennsylvania Museum of Archaeology and Anthropology, Philadelphia.

Service, E. R., 1962. Primitive social organization. Studies in Anthropology, Random House, Nueva York.

SHIMADA, I., 1987. Horizontal and vertical dimensions of prehistoric States in north Peru. En The origins and development of the Andean State, J. Haas, S. Pozorski y T. Pozorski (Eds.), pp. 130-144. Cambridge University Press, Cambridge.

- 1994a. Los modelos de la organización sociopolítica de la cultura Moche. En Moche, propuestas y perspectivas. Actas del Primer Coloquio sobre la Cultura Moche, Trujillo, 12-16 de abril de 1993, S. Uceda y E. Mujica (Eds.), pp.359-387. Universidad Nacional de Trujillo e Instituto Francés de Estudios Andinos, Lima.

1994b. La producción de cerámica en Morrope, Perú: Productividad, especialización y espacio vistos como recursos.
En Tecnología y organización de la cerámica prehispánica en los Andes, I. Shimada (Ed.), pp. 295-319. Pontificia Universidad Católica del Perú, Lima.

TAillon-Pellerin, A., 2004. Le site GUAD-88: Un site secondaire d'habitation Moche dans la basse vallée de Santa, côte nord du Pérou. Tesis de Maestría, Departamento de Antropología, Université de Montréal, Montreal.

Tello, R., J. Armas y C. Chapdelaine, 2003. Prácticas funerarias Moche en el complejo arqueológico Huacas del Sol y de la Luna. En Moche: Hacia el final del milenio. Actas del Secundo Coloquio soble la Cultura Moche, vol. 1, S. Uceda y E. Mujica (Eds.), pp. 149-183. Facultad de Ciencias Sociales, Universidad Nacional la Libertad, Trujillo.

Topic, T. L., 1977. Excavations at Moche. Tesis de Doctorado, Departamento de Antropología, Harvard University, Cambridge.

1982. The Early Intermediate period and its legacy. En Chan Chan:Andean desert city, M. Moseley y K. Day (Eds.), pp. 255284. University of New Mexico Press, Albuquerque.

Tosi, M., 1984. The notion of craft specialization and its representation in the archaeological record of early States in the Turanian Basin. En Marxist perspectives in archaeology, M. Spriggs (Ed.), pp. 22-52. New Directions in Archaeology, Cambridge University Press, Cambridge.

UCEDA, S., 2001. Investigations at Huaca de la Luna, Moche Valley: An example of Moche religious architecture. En Moche art and archaeology in ancient Peru, J. Pillsbury (Ed.), pp. 47-67. Studies in the History of Art 63, Center for Advanced Study in the Visual Arts, Symposium Papers XL, National Gallery of Art of Washington, Yale University Press, New Haven y Londres.

UCEDA, S. y J.ARMAS, 1997. Los talleres alfareros en el centro urbano Moche. En Investigaciones en la Huaca de la Luna 1995, S. Uceda, E. Mujica y R. Morales (Eds.), pp. 93-104. Facultad de Ciencias Sociales, Universidad Nacional la Libertad, Trujillo.

1998. An urban pottery workshop at the site of Moche, North Coast of Peru. En Andean ceramics: Technology, organization, and approaches, I. Shimada (Ed.), pp. 91-110. MASCA Research Papers in Science and Technology, Suplemento de Museum Applied Science Center for Archaeology vol. 15, University of Pennsylvania Museum of Archaeology and Anthropology, Philadelphia.

UCeda, S., E. Mujica y R. Morales (Eds.), 1997. Investigaciones en la Huaca de la Luna 1995. Facultad de Ciencias Sociales, Universidad Nacional la Libertad, Trujillo. 
1998. Investigaciones en la Huaca de la Luna 1996. Facultad de Ciencias Sociales, Universidad Nacional la Libertad, Trujillo.

2000. Investigaciones en la Huaca de la Luna 1997. Facultad de Ciencias Sociales, Universidad Nacional la Libertad, Trujillo.

2003. Investigaciones en la Huaca de la Luna 1998-1999. Facultad de Ciencias Sociales, Universidad Nacional la Libertad, Trujillo.

2006. Investigaciones en la Huaca de la Luna 2000. Facultad de Ciencias Sociales, Universidad Nacional la Libertad, Trujillo.

UCEDA, S.y C. Rengifo, 2006. La especialización del trabajo: Teoría y arqueología. El caso de los orfebres mochicas. Bulletin de l'Institut Français d'Études Andines 35 (2): 149-185.

UCEDA, S.y M. Tufinio, 2003. El complejo arquitectónico religioso Moche de la Huaca de la Luna: Una aproximación a su dinámica ocupacional. En Moche: Hacia el final del milenio. Actas del Segundo Coloquio sobre la Cultura Moche, vol. 2, S. Uceda y E.
Mujica (Eds.), pp. 179-228. Universidad Nacional de Trujillo y Pontificia Universidad Católica del Perú, Lima.

Van Gijseghem, H., 2001. Household and family at Moche, Peru:An analysis of building and residence patterns in a prehispanic urban center. Latin American Antiquity 12 (3): 257-273.

VAUGHN, K., 2006. Craft production, exchange and political power in the preincaic Andes. Journal of Archaeological Research $14(4): 313-344$.

Verano, J., S. Uceda, C. Chapdelaine, R. Tello, M. I. Paredes y V. Pimentel, 1999. Modified human skulls from the urban sector of the Pyramids of Moche, Northern Peru. Latin American Antiquity 10 (1): 59-70.

Wilson, D., 1988. Prehispanic settlement patterns in the lower Santa Valley, Peru. A regional perspective on the origins and development of complex north coast society. Smithsonian Institution Press, Washington D. C.

Yerkes, R., 1991. Specialization in shell artifact production at Cahokia. En New perspectives on Cahokia, J. Stoltman (Ed.), pp. 49-64. Prehistory Press, Madison. 